Journal of Education and Vocational Research (ISSN 2221-2590)

Vol. 7, No. 4, pp. 6-11, December 2016

\title{
Effects of Student's Grade to Teacher's Teaching: a Case Study in an Indigenous Classroom
}

\author{
Murni Sianturi, Huei-Hsuan Lin \\ Musamus University, Indonesia \\ National Dong Hwa University, Taiwan \\ murnisianturi06@gmail.com,linhh@mail.ndhu.edu.tw
}

\begin{abstract}
The perspective of teaching in rural area led this study to investigate non-indigenous teacher's teachings in an indigenous classroom of one of rural elementary schools in Hualien, Taiwan. The teacher's views on indigenous students' grade and how it related to the teacher's teaching were explored also. This study was a case study. Data was collected and analyzed by applying qualitative method. It implemented classroom ethnography approach. It revealed that although the teacher had demonstrated a great deal of passion in teaching indigenous students, involvement the students in some indoor and outdoor activities, and using various media to get students' attention, but he was concerned about his students' low academic achievement. In Hualien, there are annual provincial examinations on the subjects of Chinese, Mathematics and English in May, which all the elementary students are required to take. To improve the student academic performance he used some classroom time to practice drills rather than spending time on exploratory activities. When indigenous students' underperformance in standardized tests are considered as reflecting poor quality of teaching, preparing students for the sit-in tests will continue to be a part of classroom teaching. This study suggests that teachers have to understand the educational context in which teaching and learning take place. Knowing this would provide teachers a more meaningful teaching and learning.
\end{abstract}

Keywords: Teaching, grade, non-indigenous teacher, indigenous students, rural elementary school

\section{Introduction}

Including Taiwan, most of countries have tried to get a top ranking in Program for International Student Assessment (PISA). Those countries have considered that it is one of good educational level proof. As one Asia eastern country, in the 2012 Taiwan has shown a fairly outstanding achievement by obtaining the fourth ranking in Mathematics and the thirteenth in Science (Taiwan Today, 2013; Massachusetts Department of Elementary and Secondary Education, 2014). The students who took responsibility on PISA have always been rural non-indigenous students. A lot of issues regarding the incompetence of rural indigenous students (Tang, 2000; Taipei Times, 2009; Zhang \& Sheu, 2012) might be one of reasons why they do not exist in even a number of academic competitions. Tang (2000) stated indigenous students had the lowest academic achievement. More specifically, Lan, Liu \& Hsu (2013) argued rural indigenous students' academic grades were worse than urban indigenous students'. Trying to improve rural indigenous students, rural indigenous education has been at the center of Taiwanese educational reform discussion. There have been a lot of studies exploring the structural issue regarding the instability of teaching forces in rural areas (Chang \& Chang, 2014), while others focused on the cultural differences between students background and the learning materials at school (Lan et al., 2013).

Additionally some studies drew our attention to how teachers teach to investigate the core relationship between classroom teaching and indigenous students' academic outcomes (Lan et al., 2013). Tang (2002) also pointed out that in a mixed environment, teachers tended to pay less attention to indigenous students. Teachers have essential roles to make the teaching and learning meaningful. Teachers also affect students learning achievement. It would be true that teachers make choices everyday as to how to teach and what to teach in the classroom. However, the researches which investigate to how the classroom teaching occurs between non-indigenous teacher and rural indigenous students as well as the reasons of tending paying less attention to indigenous students are rare studied. Within this educational backdrop, the corresponding author of this paper conducted classroom ethnography in a rural elementary school in Hualien, Taiwan while she was a graduate student. It examined on a case study of an ethnic Han Taiwanese teacher taught Truku students there. This study particularly focused on the teacher's view of students' academic performance in relation to his teaching. 


\section{Literature Review}

According to Fan's \& Chen's study (1999), stereotype of rural students' incompetence has prevailed to be a world issue for many years. So, it is not surprisingly that in Taiwan happened as well (Taipei Times, 2009; Zhang \& Sheu, 2012). This stigma might be stimulated by existence of standardized tests as learning outcomes evaluation methods (Herzog \& Pittman, 1995).A lot of reasons become factors why rural students did not do well in academic performance, for instance family background and socioeconomic status (Kohn, 2001). Low achievement in rural area is often identically measured by grade become portray of students quality. According to Organization for Economic Co-operation and Development (OECD) in 2012, in most countries and economics, students from socio-economically disadvantaged backgrounds are more likely to receive lower marks. In fact, not only in rural education, but also generally in education field, grade becomes important. The teachers use score as measurement whether the students have mastered the lesson and keep motivation in their students (OECD, 2012).

\section{Methodology}

a. Participant: This study took place in Mingli (pseudo name) Primary school, one of the rural elementary schools in Hualien, Taiwan. This is a case study which focused on t one participant. The participant was a Han Taiwanese (non-indigenous) male teacher. This study used the snowball technique. A university professor linked and introduced the corresponding author to him when she was looking for indigenous classroom for exploration. She investigated his Mathematics and Science classes. Chang (pseudo name) was 39 years old and was studying master program in Education at the time of this study (2014). He has taught for six years in this school. In some period time, he had scheduled meetings and discussions in elementary teacher community around Hualien County. In this meeting, they usually discussed about their students and teaching. His students were mainly Truku, which is one of the ethnic tribes in Taiwan. Generally, they come from low to middle socioeconomic status. Most of the students' parents live away from them. The parents live in cities to earn money. Some of them live with their grandparent. The students were fourth grade. Totally they were sixteen students.

b. Data Collection and Analyzed: Since this study aimed to investigate how this teacher taught in his class, so data analysis was related to the classroom activities, teaching strategies and the thoughts that he put into his teaching. To collect data, this study applied observations, interviews and video recording (Yin, 2011). Observations were explored deeply to investigate classroom activities and teaching strategies. Beside observations were undertaken every week in one month, interviews were needed to strengthen gathered information from observations. Usually, after observation was done, the researcher would continue to interview him. Also, through interviews, the researcher gathered data regarding his view on student academic performance. The student worksheet and its result were considered during the interviews. Whole the classroom activities and interview were recorded to connect each other. Collected data from various methods was combined and analyzed.

\section{Results}

a. Teacher's Views on Students' Grade: The teacher's teaching experiences for six years at the school provided him more and less description of indigenous students' outcomes. From year to year, the outcomes were almost similar. Not only the fourth grade, but previously he also taught other grade. These outcomes were always being a topic in meeting of his community (this group was mentioned methodology earlier). He always compared his students' outcomes with students' ones of the other teachers. When he stated, “As we know, if we compare these students' learning achievements with urban students', ours students' are sure to be a little behind," he continued with awareness that teaching indigenous students in rural area is not easy. Not only what he thought about his students but the public stigma about stereotype of lower achievement and motivation of the students also impacted him. This reality seemed like a proof. After testing the students, he found that students' learning achievement was low. He felt so sad. He said, "It happens, I tell some students that you get $\mathrm{C}$ grade, yet they are so happy... I do not know why they are not upset. On the other hand, I was precise disappointed." He didn't know why the students' analysis ability particularly in Mathematics and 
Science is low. In classroom activities, when he came to students with questions "Why...?" and so on, most of students did not give the correct answer and just guessed it. Though, in his opinion, some questions were categorized simple ones. Yet, he assumed that this happened probably because most students hated Mathematics and Science subject. For them, those subjects were the most difficult. They preferred Sports and Art (music) subjects. "As Mathematics and Science teacher, I have to work hard to improve them", he testified.

b. Effects of Teacher Views on Student's Grade to Teacher's Teaching: Even though students' scores were low, but he had shown a passion in teaching his students. He testified, "As I said before, that most of them hated Science and Mathematics in the beginning, yet now they have progressed, at least they are actively involved in learning." So to face the situation, the approaches used in his teachings were introduced. He stated, "It started from me to them... I need to think more of my teaching."He somewhat understatedly explained, "This situation challenged me to improve my teaching, and we have teachers' community in where we can share our problem every month". So, from his view on the students' grade, he tried to design his teaching with a hope that the students' academic performance would improve. He arranged such as conducive classroom activities, student engagement, and applying various media.

Classroom Activities: Both of Mathematics and Science classes Chang usually arranged his classes by starting disclosure, core and closure activities. In disclosure time, he provided visual illustrations related to the topic. Sometimes he started by raising questions and asked the students to guess the answers. Usually students were responsive to his questions and eager to answer. From students' responses I could tell that the sequence of the nature of the questions. It became harder and harder as students took more time to think and their participation became gradually reserved. In addition to question and answer, sometimes the teacher divided students into four groups heterogeneously. In two subjects, he used the grouping for different purposes. In Science class students conducted experiment in groups, while in Mathematics class students practiced drills in groups. Moreover, he incorporated the use of media in his teaching frequently. These were examples of his classroom activities. The Science's topic entitled "light". He started by using the projector to show students the sunshine in the forest. Then, he asked, "What do you see?" Each student gave their responses. Based on the students' responses, he continued to ask them, "In the forest, why some parts are dark and while other areas bright? Why can you see something?" These questions led students to understand light and its benefit in their lives. He continued to further the agenda by introducing shadow. Some experiments were done by students in groups. Students would also watch films, and after discussions were held and study sheets given to fill. Meanwhile, in Mathematics class, at the beginning of Mathematics topic regarding fraction, he chose pizza as an illustration. In this learning, he applied more computer and its applications. Afterwards, he gave some drills to students. He spent more time to give drills rather than exploratory. He commented, "Giving more tasks and practices would provide the students skill in doing Mathematics test."

Student's Engagement: In classes, the students did not feel afraid to give their responses. They would raise their hands, and gave their responses, even though some of their responses were not related to the teacher's questions. However, if so the teacher would ask others to complete the students' responses. Even, when they had some questions they would ask him soon. In his teachings, they were actively engaged. Sometimes he made some jokes, and funny expressions, so they laughed together. Also, he had lunch together every day and had same menu with the students in the classroom. While enjoying lunch, he played the movie about the Science topic that was previously taught. He indicated that this was a reality which their learning achievement was based on the students' ability. He also understood that their Mathematics and Sciences ability were different each other. In students groups, he tried to overcome this by involving them whose higher scores to help their other classmates. He somewhat understatedly explained:

“The students' abilities are different. I describe it as stairs, by putting each student's based on their level.... In some cases, if I found that some students did not understand the topics, I explained again or asked other students to help the students."

He also engaged them in some indoor and outdoor activities. Especially Mathematics class, they learned through indoor activities. Differently, in Science class, they enjoyed the outdoor time when they were doing experiments. Besides learning Mathematics and Science topics, he also arranged some reading time in the 
classroom. They had a small library. Sometimes, before starting class, he invited them to read some books that they liked. Some of them would sit nearby each other. They exposed and shared what they read each other. So learning occurred both indoor and outdoor time. Because of these activities, most of them began to enjoy Mathematics and Science classes.

Emphasizing in Using Media: He emphasized that it is important to use various resources when teaching. He tried to use simple media such as recycled materials such as cups, buckets, sticks, mirrors, scissors, and also money. Teacher Chang also incorporated more sophisticated tools such computer, laser and PAD. Foremost, he was pretty well in applying technology. Playing movie, designing PPT, giving each students PAD, even applying game which related to learning are examples of ways he implemented technology in his teaching. The day before teaching, he would ensure that the media to be used on the following day was in the classroom. He also made sure that would relevant and would be applied properly. In addition, when it came to lessons that would involve illustrations, he would practice at home. Sometimes he did not take any rest at break time, due to the need to prepare the material and media for next class. These methods he used to reach the needs of the rural students. Moreover, when he measured students' learning achievement through test, he would write questions and then send it to one application that is shared by internet connection. By using sophisticated equipment, he thought that students would be more motivated to learn, so that their grades increased.

Discussion: There is an inconsistent and conflicting phenomenon in Taiwan: On one hand there are a lot of educational discussions regarding education and how it should meet the needs of students of various backgrounds. On the other hand, there is an increasing demand in terms of the quantification of evaluation. People want to see "results" in a way which is quick, definite and usually numerical. Test scores thus become a common and popular way to evaluate quality. Scoring is solely obtained during a one point time interval and is indeed very unfair to be an indicator of learning. From what I observed of this rural classroom, during learning process, most of students were enthusiastic and actively engaged. According to the teachers, students had come a long way to change their learning attitudes toward Science and Mathematics; they are courageous to speak out and respond to the teacher's questions. Unfortunately students still did not do well in the tests. What is the meaning of failing grades? Does the low score represent that student fail to learn? There are some education discussions that warn us that overemphasis on score might be detrimental to learning (Kohn, 1999b; 2008). Kohn (2011) emphasized to switch educational focus onto the psychological and pedagogical rather than on grading. The Kohn's research (2011) found that there were three impacts of grading students' learning, i.e., reducing of student's attention about learning; choosing to undertaking the easy tasks due to the desire to get high scores, and getting common thinking and easy to forget the topic. Kohn (2011) stated grades were inclined to diminish students' interest in the learning itself.

Those results seemed inversely to the claimed test function in which it was believed to provide standard to schools, teachers and to support students; as a feedback of classroom instruction; to increase the teacher accountability for student learning and promote the change in education reform (Herman \& Golan, 1991). However, currently it has gained and increase in criticisms. Many studies have surfaced asking whether scoring assesses the students' ability completely, and whether increasing scores performance represents the increasing students' learning. The scoring which was used was too narrow (Popham, 2001; Gardner, 2006). Moreover, in Hualien County there are annual provincial examinations on the subjects of Chinese, Mathematics and English in May. All of the elementary and junior high students in the county are required to take this examination. Though the score will not be counted into students' individual records, the official academic supervisors will pay special visits and conduct classroom observations to those classes whose average scores are in the last $10 \%$ stratum. In other words, the poor collective scores are perceived as a reflection of poor quality of teaching. As a result, the teacher used some classroom time to practice drills with a hope to increase students' grade rather than spending time on exploratory activities. This situation certainly affects teachers. Such as finding of this study, the scoring itself has influenced on his planning and implementation of instruction. Concerned about the lower students learning achievement, the teacher who taught the rural students as well as indigenous students who were not interested in the Mathematics and Science subjects tried to design the lessons by arranging the classroom activities, making relations with students as well as implementing the media and giving more drills to enable the students' understanding of 
the topic. Though the teacher was able to motivate himself within the low grade by integrating sophisticated instructional media, he was certainly under pressure. In psychology, working without pressure must be better. The finding of Fish's study (in Herman \& Golan, 1991) stated teachers reacted negatively to the pressure created by the scores of their classes.

The paradigm that students learning achievement is measured by score will decrease the meaning of student's learning achievement itself. Such as in this study, even though the students started to like Mathematics and Science subjects, but because the students' scores were still low, he thought that the teaching was failed. Rationally, indeed score may help teachers to find out the educational purposes are, and then identify whether we have been flourishing within by measurement. However, currently measurement is dominating the teaching and learning process (Kohn, 1999a; 2011). Unfortunately, common forms of assessment lead the teaching and learning become terrible. Recent studies have provided an overview to switch from conventional grading. Some of them decided to deploy an effective assessment in learning is more accurate, consistent, in-depth understanding, and supportive (Hawley, 2007, p. 35-37, 90-92; Guskey, 2011). Others developed authentic assessment that measured the success of students with a variety of ways (Chen, Krechevsky \& Viens, 1998). The more extreme might by eliminating grading, since to find whether a student has mastered the lesson doesn't require tests, and show it doesn't oblige grades, even, without either, student would be better in future (Kohn, 2011). When teacher emphasized the score as assessment, the meaning of the teaching and learning might be decreased. They will lose the sense of learning psychology and pedagogic. Giving more attention on a student's needs rather than the score will help the teacher in teaching and student in learning. Encouraging the students become more interested in what they are doing would be more meaningful and able to lift the student's sights (Redding \& Walberg, 2012). Many of the students in rural areas might learn valuable life skills at home, but don't necessary get the support from home regarding their academic learning. Therefore there is discrepancy between how and what they learned at home and at school. Moreover, a lot of rural students are also indigenous students who have different cultural background with non-indigenous ones. As a result they need more time and learning strategies which are activityoriented, rather than lecture-oriented. The traditional paper-pencil tests might not be an effective way to gauge how well they learned.

\section{Conclusion}

According to this finding, the study concluded that score affected teaching of a Han Taiwanese teacher. During his teaching process, the teacher arranged his classroom activities properly, and implemented various media from simple to sophisticated ones which created a good relationship with the students. However, problems still arose and when faced the indigenous students' scores became the focus of his teaching arrangement. The lower grades of students impacted the Han Taiwanese teacher. Despite this situation raised Han Taiwanese' efforts to improved students' grades, but in fact Han Taiwanese somehow feel depressed. The grade itself impacted to ways of Han Taiwanese teacher taught the students. Based on the findings, this study suggests that when conducting classroom ethnography with regard to teaching, we have to understand the educational context in which teaching and learning takes place. A teacher's teaching is informed by his or her philosophy, knowledge, as well as the educational policies. When indigenous students' underperformance in standardized tests are considered as reflecting poor quality of teaching, preparing students for the sit-in tests will continue to be a part of classroom teaching. When the educational discourse focuses on training teachers to teach in ways which are appropriate to students with various cultural and social backgrounds, we also need to pay attention to what extent the over cultural and educational structures which encourage, instead of prohibiting meaningful learning to happen.

\section{References}

Chang, C. N. \& Chang, L. Y. (2014).The influence of family and school factors on student achievement in rural Taiwan. Presented in ECER 2014, The Past, the Present and the Future of Educational Research, European Educational Research Association. Retrieved http://www.eera-ecer.de/ecerrogrammes/conference/19/contribution/30863/.Accessed 15 th November 2014. 
Chen, J. Q., Krechevsky, M. \& Viens, J. (1998). Building on Children's Strength: The Experience of Project Spectrum. New York. NY: Teachers College Press.

Fan, X. \& Chen, M. J. (1999). Academic achievement of rural school students: A multi-year comparison with their peers in suburban and urban schools. Journal of Research Education, 15(1), 31-46.

Gardner, H. (2006). Multiple intelligences: New horizons. New York: Basic Books.

Guskey, T. R. (2011). Grading reform. Educational Leadership, 1, 17-21

Hawley, W. D. (2007).The Keys to Effective Schools: Educational Reform as Continuous Improvement (2 ${ }^{\text {nded.). }}$ United States: National Education Association.

Herman, J. L. \& Golan, S. (1991). Effects of standardized testing on teachers and learning- another look. National Center Research on Evaluation, Standard, and Student Testing, 1-73.

Herzog, M. L. R. \& Pittman, R. B. (1995).Home, family, and community. Ingredients on the rural education equation. Phi Delta Kappan, 77, 113-118.

Kohn, A. (1999a). From degrading to de-grading. High School Magazine, 1-10.

Kohn, A. (1999b). The costs of overemphasizing achievement. School Administrations, 1-6.

Kohn, A. (2001). Fighting the tests: A practical guide to rescuing our schools. Phi Delta Kappan, 1-16.

Kohn, A. (2008). It's not what we teach; it's what they learn. Education Week, 1-3.

Kohn, A. (2011). The case against grades. Educational Leadership, 28-33.

Lan, C. J., Liu, R. L. \& Hsu, L. M. (2013). The study of learning of college nursing aboriginal students in Taiwancombine both longitudinal and cross-sectional methods. Journal of Modern Education Review, 3(8), 587-603.

Massachusetts Department of Elementary and Secondary Education. (2014). PISA Results. Malden. Retrieved http://www.doe.edu.Accessed $3^{\text {rd }}$ December 2014.

OECD. (2012). Grades Expectations: Hoe Marks and Education Policies Shapes Students' Ambitions. PISA: OECD Publishing.

Popham, W. J. (2001). Teaching to the test? Educational Leadership, 58(6), 16-20.

Redding, S. \& Walberg. H. J. (2012). Promoting Learning in Rural Schools. Lincoln: Center on Innovation and Improvement.

Taipei Times. (2009). The urban-rural gap in education. Retrieved http://www.taipeitimes.com/News/editorials/archives/2009/07/19/2003449021.Accessed $\quad 25^{\text {th }}$ November 2014.

Taiwan Today. (2013). Taiwan Moves up to $4^{\text {th }}$ in 2012 PISA Math Ranking. Retrieved http://www.taiwantoday.tw/ct.asp?xitem=212286\&CtNode=416.Accessed 24th November 2014.

Tang G. D. (2000). A review and prospects of educational revolution of aborigines. Aboriginal Culture and Education Communications, 5, 5-11.

Tang G. D. (2002). A longitudinal study of adaptation and loss issues of aboriginal junior high school students. Report of Special Subject Plan by National Science Council: NSC 90-2413-H-003-005.

Yin, R. K. (2011).Qualitative Research from Start to Finish. New York, NY: Guilford.

Zhang, L. C. \& Sheu, T. M. (2012).Effective Investment strategies on Mathematics performance in rural area. Science and Business Media, Springer, 1-19, doi: 10.1007/s11135-012-9752-x. 